\title{
Understanding the next of kin's experience of their life situation in informal caregiving of older persons
}

\author{
Elisabeth Liedström ${ }^{1}$, Kirsti Skovdahl ${ }^{1,2}{ }^{2}$ Ann-Kristin Isaksson ${ }^{1}$, Jenny Windahl ${ }^{1}$, Annica \\ Kihlgren ${ }^{1}$ \\ 1. School of Health and Medical Sciences, University of Örebro, Örebro, Sweden. 2. Faculty of Health Sciences, Buskerud \\ University College, Kongsberg, Norway.
}

Correspondence: Elisabeth Liedström. Address: School of Health and Medical Sciences, University of Örebro, S-701 82 Örebro, Sweden. Email: elisabeth.liedstrom@oru.se

Received: October 6, 2013

DOI: $10.5430 /$ cns.v2n1p53

Online Published: December 16, 2013

Accepted: December 3, 2013

\begin{abstract}
The experience of their life situation of next of kin in informal caregiving needs to be followed as they may need support to maintain their own health and cope with continuing in their caregiving role. Many of these individuals, often the older person's spouse, are elderly themselves. The aim of this study was to increase the understanding of the next of kin's experience of their life situation in connection with their informal caregiving of older persons. The study had a qualitative approach, with an inductive explorative design. Informal conversational interviews were conducted. Twelve next of kin were interviewed, nine of them twice. In all, 21 interviews were performed, and subsequently subjected to latent content analysis. The theme that emerged from the data was "A balance or imbalance in next of kin's daily life." The three subthemes were: (1) Balance and imbalance in the relationship with the older person, other family members, and friends; (2) Balance and imbalance in the relationship with the staff from municipal care; and (3) Balance and imbalance in demands, affecting the caregiver's own health. Communication with mutual respect was described as a tool for creating good relations. The results of this study highlight the strained life experiences of next of kin while caring for older persons. There is a need to give more attention to the next of kin's life situation and to find the means to support them. To reduce worry and stress, health care staff need to understand the next of kin's experience of their life situation, and good relations need to be created among all involved in the care.
\end{abstract}

\section{Key words}

Next of kin, Informal caregiver, Life situation, Older person, Municipal care

\section{Introduction}

The proportion of older persons is expected to increase in the Western world as their health improves ${ }^{[1]}$. In Europe, around $20 \%$ of the population is over 60 years of age ${ }^{[2]}$. The number of people aged 65 and above is expected to grow by $70 \%$ by the year 2050, putting additional demands on the health care sector. As a result, the health care sector needs to be adapted to the needs of an aging population and a smaller workforce ${ }^{[3]}$. Furthermore, an ongoing global and national effort is under way to improve health among older persons. Due to medical advances, older persons survive longer now than before and for this reason, there is an increased need for health care during the final years of life ${ }^{[4]}$. Sweden is among the top ten 
countries when it comes to having the largest proportion of the population aged 60 or more: $25 \%$ of Swedes are in this age $\operatorname{group}^{[5]}$.

A growing number of older persons continue to live in their own homes. This is not due to a declining need for care, but to limited nursing home places. In the final stage of life, most people are exposed to increasing health problems, generating a substantial demand for health and social care. As a result, older persons often need help from their next of kin ${ }^{[6]}$. The term next of kin is often used to describe someone who cares for a person, who may also be called an informal caregiver ${ }^{[7]}$.

In Sweden today, $75 \%$ of the care of older persons is provided by the person who usually is closest to them — the next of kin ${ }^{[8]}$. The time pressure resulting from giving care can cause problems for the next of kin regarding their work situation and can lead to strained family relationships ${ }^{[8]}$. There is a relationship between care provision and self-estimated health status. The risk of illness in caregivers increases in relation to an increase the extent of care they provide ${ }^{[8]}$. In one study, the next of kin experienced greater cognitive difficulties and poorer mental health than did demographically matched, married, non-caregiving controls ${ }^{[9]}$. Extensive research has been done during the past 20 years on the life situation of caregiving next of kin, documenting their burden of care ${ }^{[10-17]}$. Studies of informal caregiving have focused on the caregiving of older persons who are cognitively impaired, and on the tasks, burdens, and socioeconomic impacts of informal caregiving in families ${ }^{[18]}$. In Sweden, as in the other Nordic countries, society has the responsibility for people in need of care ${ }^{[8]}$. The National Board of Health and Welfare is obliged by law to individually support the caregiving next of kin of a person who is older, disabled, or chronically ill. Consequently the health and welfare authorities, specifically in the municipalities, shall pay attention to the next of kin's life situation ${ }^{[19]}$.

There are different ways to support the next of kin, such as to set up kin support groups with other next of kin who are in similar situations ${ }^{[20]}$. A model developed by Nolan and colleagues, called the Partnership Model, is of relevance ${ }^{[21,22]}$. It offers a means of closer cooperation between staff, on the one hand, and the older person and his or her next of kin, on the other hand. Nolan and colleagues propose that the model has a role to play in nursing education ${ }^{[21,22]}$.

Many of the next of kin are old themselves, often being the older person's spouse. The next of kin's experience of their life situation therefore needs to be closely followed, as they may need support to maintain their own health and cope with continuing in their caregiving role ${ }^{[23]}$.

Further studies within this area are needed, as commitments from next of kin are expected to increase over time because of the growing older population and economic constraints in the health care system. Therefore, the aim of this study was to increase the understanding of the next of kin's experience of their life situation in connection with their informal caregiving of older persons.

The term "next of kin/informal caregiver" in this study is the individual, a family member or a friend, who provides assistance in the intimate environment of the dependent person.

\section{Method}

\subsection{Design and setting}

The study had a qualitative approach, with an inductive explorative design. Qualitative methods are considered appropriate when the aim is to gain knowledge of a person's experience of a phenomenon or to understand an emic (insider) perspective ${ }^{[24]}$. Informal conversational interviews were performed with twelve next of kin, which is the most open-ended approach for interviewing. The interview offers maximum flexibility to pursue information in whatever direction appears to be appropriate, depending on what emerges from talking with the participant ${ }^{[25]}$. The interviews were analyzed by latent content analysis, which implies an analysis of what the text talks about and an interpretation of the 
underlying meaning of the text, which can vary in depth and level of abstraction ${ }^{[26]}$. The research project was approved by the regional ethical review board in Uppsala (Reg. No. 2011/009).

\subsection{Recruitment}

The present study is part of a major project whose overall aim was to explore what a meaningful everyday life is for older persons $\geq 65$ years of age ${ }^{[27]}$. During the project, the managers asked the included older persons who were receiving home care or lived in a nursing home whether they were willing to submit the name of their next of kin for possible participation in the present study. Twelve older persons agreed to give the name of their next of kin, and the managers then provided us with a list of twelve names. The inclusion criterion was being the individual whom the older person had named as his/her close person. There were no restrictions on who could be the next of kin; consanguinity was not a requirement.

The next of kin received written information from the manager of the unit and left a signed informed consent form with the staff, who forwarded it to our group. Subsequently, the first author (E.L.) contacted the next of kin by telephone, to give them more information about the study and to ask whether they were still willing to participate in the study, stressing that participation was voluntary. All next of kin who were asked to participate agreed, in total seven women and five men. The participants had experience of different types of municipal health care. All of them had experience of home care, in seven cases including nursing home care, and four also had experience of respite care or day care.

Table 1. Demographic data on next of kin

\begin{tabular}{|c|c|}
\hline & All next of kin $(n=12)$ \\
\hline Age, yrs (mean) & 59 \\
\hline (range) & $44-80$ \\
\hline \multicolumn{2}{|l|}{ Gender (number) } \\
\hline Women & 7 \\
\hline Men & 5 \\
\hline \multicolumn{2}{|l|}{ Civil status (number) } \\
\hline Living alone & 3 \\
\hline Married, or cohabiting with partner & 9 \\
\hline \multicolumn{2}{|l|}{ Working situation (number) } \\
\hline Working full-time & 8 \\
\hline Working part-time & 1 \\
\hline Retired & 3 \\
\hline \multicolumn{2}{|l|}{ Relationship with older person (number) } \\
\hline Spouse, cohabiting & 2 \\
\hline Spouse, not cohabiting & 1 \\
\hline Sibling, not cohabiting & 1 \\
\hline Adult child, not cohabiting & 8 \\
\hline
\end{tabular}

\subsection{Data collection}

Informal conversational interviews ${ }^{[25]}$ were conducted to increase the understanding of the next of kin's experiences of their life situation in connection with informal caregiving of older persons. All interviews were conducted by the first author (E.L.) who started the interviews with a general question: "How do you feel about your life situation?" Follow-up questions were asked, for instance, "What do you think about that?" and "How do you feel about that?" The interviews 
were conducted as conversations, where the participants were encouraged to speak as freely as possible. After the first interview, each participant was sent a transcription of his or her interview by post, to read before the second interview; this was done to give the participant a chance to reflect on what had been said, making for a richer conversation the next time. Before the second interview, the author read the transcripts and made notes. In the second interview, follow-up questions were asked, such as: "What have you been thinking about it all since the last time we met?" and "What did you mean by ...?" In this way, the earlier interview were extended. Nine participants were interviewed twice. One said that one interview was enough, given the lack of time; one canceled the second interview without giving a reason, and one was not reachable after the first interview. Consequently, there were 21 interviews in total. The interval between the first and second interviews varied from 4 weeks to $3 \frac{1}{2}$ months. Each participant chose the location for their interview(s). Data collection took place during the period May 2011 to February 2012. Each interview lasted from 1 hour to $1 \frac{1}{2}$ hours. All interviews were recorded on an MP3 player and transcribed verbatim by the first author (E.L.), with inclusion of all expressions of emotion.

\subsection{Data analysis}

The first author (E.L.) read through the transcripts several times to acquire a general sense of the whole. Meaning units related to the same central meaning and relevant to the aim of the study were identified. The meaning units were then condensed into a description close to the text to grasp the manifest content. In the next step, the underlying meaning in the condensed meaning units was interpreted to determine the latent content. The condensed meaning units were then seen as a whole, reflected over, and abstracted into three subthemes, threads of meaning running through the condensed text. The subthemes constructed a theme, "A balance or imbalance in next of kin's daily life" ${ }^{[26]}$. Throughout the process of analysis, all authors scrutinized and repeatedly discussed the results to ensure the trustworthiness of the data analysis and the best form of presentation (see Table 2).

Table 2. Examples of meaning units, condensed meaning units, sub-themes, and theme that emerged from the latent content analysis

\begin{tabular}{|c|c|c|c|c|}
\hline Meaning unit & $\begin{array}{l}\text { Condensed meaning } \\
\text { units }\end{array}$ & $\begin{array}{l}\text { Interpretation of } \\
\text { the underlying } \\
\text { meaning }\end{array}$ & Sub-themes & Theme \\
\hline $\begin{array}{l}\text { I just pointed out that he'd never been } \\
\text { able to go out. But "Oh," they said, } \\
\text { "we'll arrange that." Then nothing } \\
\text { happened. Oh, I know he didn't go out } \\
\text { even once. }\end{array}$ & $\begin{array}{l}\text { has never been able to go } \\
\text { out ... we'll arrange that ... } \\
\text { then nothing happens }\end{array}$ & $\begin{array}{l}\text { Negative encounters } \\
\text { in care: lack of } \\
\text { support }\end{array}$ & $\begin{array}{l}\text { Balance and } \\
\text { imbalance in the } \\
\text { relationship with } \\
\text { the staff from } \\
\text { municipal } \\
\text { care }\end{array}$ & \\
\hline $\begin{array}{l}\text { There's nobody, nobody who's got } \\
\text { time. Well, yes, my friends... [cries]. } \\
\text { But I don't want to sit and get on } \\
\text { people's nerves going on about it. No } \\
\text { [sadly], I haven't asked for anything } \\
\text { either. You've got to cope, haven't } \\
\text { you? }\end{array}$ & $\begin{array}{l}\text { Nobody has time ... yes, } \\
\text { my friends ... get on } \\
\text { people's nerves... you've } \\
\text { got to cope, haven't you? }\end{array}$ & $\begin{array}{l}\text { Support from } \\
\text { friends. } \\
\text { Feeling of loneliness }\end{array}$ & $\begin{array}{l}\text { Balance and } \\
\text { imbalance in the } \\
\text { relationship with } \\
\text { the older person, } \\
\text { other family } \\
\text { members, and } \\
\text { friends }\end{array}$ & $\begin{array}{l}\text { Balance or } \\
\text { imbalance in } \\
\text { next of kin's } \\
\text { daily life }\end{array}$ \\
\hline
\end{tabular}

I want to be in touch with people who are a bit bright and happy, I think, because then I can forget my own concerns, can't I? I think that'll heal my wounds better. But now I can't get my insulin level right, and that worries me a lot. It makes me feel a bit down. But maybe it'll turn out all right.
Want to be in touch with bright and happy people ... now I can't get my insulin level right, and that worries me a lot. Feel a bit down.

\section{Needs support and} in need of friends. Worried about health
Balance and imbalance in the demands affected one's own health 


\section{Findings}

The theme "A balance or imbalance in next of kin's daily life" emerged from the subthemes, which were: (1) Balance and imbalance in the relationship with the older person, other family members, and friends; (2) Balance and imbalance in the relationship with the staff from municipal care; and (3) Balance and imbalance in demands, affecting the caregiver's own health.

The theme describes how the next of kin experienced the interaction with other persons and the demands that affected their own health and daily life. Communication was described as a tool for creating a good balance in relations with others. However, communication had to be based on mutual respect between the next of kin, the older person, and the staff from municipal care, and it was important for the next of kin to be taken seriously and to feel involved in the care that staff were providing.

\subsection{Balance and imbalance in the relationship with the older person, other family members, and friends}

A balance or imbalance in the interaction with the older person, family members, and friends was seen in the next of kin's experiences of daily life. The next of kin lived in a shrinking world where the care of the older person took up most of their time, and where little time was left to other family members and friends. Some described their relationship with the older person as undemanding, with good communication and mutual respect. They also described feelings of humility and accountability, with the older person making no demands (spoken or unspoken). They felt that they were playing an important role in the older person's life.

Others related how they had had a tough time for several years before the older person secured a place in a nursing home. One participant described her life situation as a "difficult journey" which she did not "know how to survive" (next of kin 3). When the older person a next of kin had provided care to had moved to a nursing home, the next of kin often felt a certain sense of freedom, but at the same time felt guilty for having "abandoned" the person. Some next of kin felt controlled by the older person, the latter always wanting to know what they were doing and where they were. They never got positive feedback from the older person, who was sometimes mean and nasty and behaved offensively. The situation could be experienced as one of overwhelming demand, of always having to help in spite of receiving so little kindness or understanding in return. The next of kin sometimes thought that they and the older person did not aspire to the same goals. One participant related:

No generosity and almost a bit on the offensive side, he could say things like, "Do you think there's much point you coming here a couple of days a week? I can't go on like this, I'm going to die, I can't cope. So you're going away over the weekend - well all right, I'll die then ..." (Next of kin 4)

Some participants described a feeling of loneliness deriving from never feeling loved by the older person. A different kind of loneliness that was mentioned, experienced by one participant who was cohabiting with the older person, resulted from difficulties with intimacy and sex. In this respect, there had been a change in the relationship, and the participant said he left the room when love scenes were shown on television, because they were too difficult to watch. The lack of intimacy and sexuality had been an important part of their relationship. Part of the problem was that the next of kin perceived it as taboo to take up the matter with the partner, and this made it difficult to feel close to the older person.

Several participants also spoke of inner conflicts and a bad conscience with regard to other family members and friends, as spending so much time caring for the older person meant that they did not have time for others. Thus their social life had deteriorated. In addition, though they wanted to be involved in the care of the older person, they often had difficult work situations that made it problematic to combine caregiving with earning an income. When the participant was the only child of the person he or she was caring for, there was mention of missing having a brother or sister to talk to and share the 
responsibility with. By contrast, those participants who did have siblings reported that they did not get much help from them. They felt that they had to shoulder the responsibility all on their own, and wanted their siblings to show more interest in participating in the care, or at least to be ready to discuss it. As one participant said:

My brother just refuses. He goes there on Christmas Eve and when it's her birthday. (Next of kin 10)

Some of the participants did not have any friends left, because of being unable to spend time with them; it was difficult to feel they belonged in a social circle or had a social life. One participant said that whenever she took the time to visit a friend, she had to sneak out without telling the older person she was going because she experienced feelings of guilt and a bad conscience. She said,

I've got no chance to meet my friends, because when I've got an hour off or I've finished work for the day, I go home to Mum. Then I don't feel up to anything else. (Next of kin 12)

\subsection{Balance and imbalance in the relationship with the staff from municipal care}

The participants said that relations with the staff in municipal care affected their life situation in several ways. There was balance or imbalance in the interaction between the next of kin and the staff depending on whether the communication was good and mutual respect existed between them. The participants felt that it was very important to be able to participate in the care of the older person and also to have the same aims regarding the care provided as the staff. For example, one participant related that the staff had called her and said: "We just wanted to tell you he's much brighter and he's sitting up now. The staff ring up and say he's better too!" (Next of kin 2).

Some participants spoke of the struggle to find a place in a nursing home for the older person, as places are limited. The waiting lists are long - and it may take more than 6 months to secure a place. During the wait, they got relief from the burden when the older person went into respite care for a few weeks. In some cases, respite care was provided repeatedly, with 2 or 3 weeks between periods of respite care. Others told of the relief they got when the older person attended day care for a few hours a week.

However, participants felt frustrated that there was too little information given out by the municipal staff, and that decisions were often not followed up. The participants described difficulties in communicating with the municipal health care staff about this problem because of the difficulty of getting in touch with the right person.

The participants wondered what role the staff expected them to play in the older person's care and where to draw the line between the next of kin's concern with his or her own life and his or her care of the older person. The next of kin were aware of the danger that they often took on too much, and said that sometimes it was exhausting.

Another source of frustration for the next of kin was, in situations where they and the older person were cohabiting, that the home care staff would simply "take over" on arriving. They felt this especially keenly when the communication with the staff was unsatisfactory. Some felt that they could not say what they wanted because they were dependent on the staff. There was mention of a perception that the staff made them feel that their home belonged to the staff, not themselves, for instance when staff did not take sufficient account of either the older person or the next of kin. One participant said: "I don't see why I should have to change everything for their [the staff's] sake." (Next of kin 3) Another said, "This is their workplace — but it's our home too." (Next of kin 9)

The participants' experience of their life situation was also affected by high staff turnover at municipal care, which gave them the perception of a lack of continuity in the home care. The person assigned responsibility for the care was often replaced or was difficult to get in touch with. There was mention of home care staff as being there but not present. Some 
next of kin described the period with home care as tough, and as providing no security. They felt powerless and could not trust the care, which meant stress and a sense of having too much responsibility. Furthermore, there had been incidents of staff saying disrespectful and insulting things to the older person, which upset the next of kin also. One participant reported:

There've been people who've been to Mum's and said things like, "We've talked about it in the group and we can't understand how she can have three dinner plates here in the sink." It's so insulting. Then they can say they're only going to wash up one of them. They go and tell this to Mum as well. I think it's so unprofessional. (Next of kin 4)

The next of kin's life situation was also affected when the older person did not thrive at the nursing home for respite care. In this respect, there was mention of poor communication between the next of kin and both the older person and the staff. One older person in respite care needed to have porridge in the morning for the sake of his stomach, but at the care centre, everyone was given soured milk, or nothing, in the morning. A member of the staff had said to the old man: "Don't go thinking it's the same as at home. Your wife has just you but we've got quite a few." (Next of kin 9) The man found it so unpleasant at this respite care center that he could not stay for 3 weeks, but went home after 4 days. Consequently, his wife got very little relief, and she was upset and angry about the fact that both her husband and she had been treated so insultingly.

\subsection{Balance and imbalance in demands, affecting the caregiver's own health}

A balance or imbalance in the demands put on them affected the next of kin's health. It may be satisfying to be able to help someone you love, but many of the participants lived with a mental unrest that was affecting their health. An imbalance appeared when the next of kin referred to their health as a part of their life situation, where their own illness made it hard for them to find the strength to care for the other person. One went so far as to say: "I've got a worse quality of life than he has - yes, I really do think it's worse." (Next of kin 3)

When the older person was living alone, the next of kin felt insecure, and afraid that something bad might happen. There was constant fear that the older person would go out without knowing where to go. In some cases, this had already happened several times, and although nothing dangerous had happened, the next of kin was worried that something bad might happen next time. One participant said,

Before, when he lived on his own, he'd be out walking during the night, barefoot and in his nightshirt, but nothing bad happened. He met up with people who took action, like call the police. (Next of kin 2)

The next of kin spoke of sadness and guilt in relation to being unable to arrange a better life for the older person. Participants who had their older person living in a nursing home also mentioned guilt; they found it difficult to let go of the responsibility. As one participant said, "I usually cry when I leave there — oh, it's so hard! I think of everything I can do (Next of kin 3)

It emerged from the interviews that the participants believed that it was required of them to be strong and help the older person, and that they thought they had no right to complain. They often accepted the situation and asked nothing for themselves, not knowing what else they could do. Some participants said that they were looking forward to better times, with more freedom. One way to get a better balance was to reduce their hours of caregiving. They did this by putting greater demands on the older person and giving more attention to their own concerns. They also made use of day care or respite care - however, this was often linked to feelings of guilt, as discussed above. It was therefore difficult to find a balance. One participant said, 
I can't work $100 \%$, so it has to be $80 \%$ at most, so that I can have a day off. She's my second job. All the same, I think I've become tougher. I've become better at relaxing. (Next of kin 4)

\section{Discussion}

The results show that the participants often found it difficult to keep a balance regarding their informal caregiving of older persons and that this affected their life situation. They found that the world around them was shrinking while they were in the caregiving situation, which afforded them little contact with others. They needed to find a balance in the relationship not only with the older person, but with other family members, and friends. Good communication was key to a balanced relationship with the staff from municipal care and a tool for creating good relationships. Mutual respect between the next of kin, the older person, and the staff from municipal care was important. Feeling accepted as a partner in providing care gave the next of kin a sense of belonging and security. Each individual who participates in a dialogue needs to be seen as an equal and at the same time be able to learn from the other participants. Human relationships are based on equality and mutual respect for each other ${ }^{[28]}$. The next of kin's life situation was affected by the balance (or imbalance) in the relations with the older person, other family members, friends, and the staff from municipal care. Their life situation and their own health were also affected by the state of balance (or imbalance) in the demands they met as informal caregivers. One way for society to create a balance for informal caregivers is to create kin support groups, such as the Partnership Model proposed by Nolan et al., which emphasizes the importance of good communication and good relationships ${ }^{[21,22]}$.

The model consists of a framework involving six "senses" that are seen as prerequisites for good relationships and good communication through dialogue, within the context of care and service delivery. Good care can only be delivered where there is a triadic relationship, in which all three parties involved in the care understand which "senses" are involved and how each of these "senses" is affected in the care situation. Each party, the older person, the next of kin, and the staff, has a key role to play and has unique knowledge to contribute. All parties should experience a sense of security (simply feeling safe), a sense of continuity (perceiving links and connections), a sense of belonging (feeling a part of things), a sense of purpose (having one or more goals to aspire to), a sense of achievement (making progress towards these goals), and a sense of significance (feeling that they matter as a person) ${ }^{[21,22]}$. What is meant by "good" communication is that there arises a feeling, an emotional feeling, that something positive has happened ${ }^{[29]}$. Below, we will discuss the results of the study in light of these six "senses".

The next of kin thought that it was mostly easy to communicate with the staff at the nursing home. This gave them a sense of significance and a feeling of belonging, and a belief that they mattered as a person and were a part of the care of the older person. They had a sense of continuity when mostly the same staff were involved in the care of the older person, and this made them feel more secure.

By contrast, they experienced that it was more difficult to communicate with the home care staff. In this context, the participants said that they were unable to say what they thought without being regarded as difficult and demanding. This finding is supported by Häggström et al ${ }^{[30,31]}$. The results of the present study show that a high rate of staff turnover within home care contributed to the next of kin's experience of lacking a sense of continuity. It was difficult to establish a good relationship with the staff when the next of kin did not know who was coming from one time to the next.

Furthermore, our results show that the next of kin lost their sense of security when they found themselves having to speak up for the older person's interests regarding collaboration with the staff. As Twigg and Atkin ${ }^{[32]}$ put it, caring takes place within a relationship and involves a feeling of responsibility towards the person being cared for. The next of kin in the present study experienced a lack of security when there was lack of communication and a high staff turnover, which created a lack of continuity. Under those circumstances, it was difficult to have a sense of purpose or achievement. Ahlström and Wadensten ${ }^{[33]}$ report that having a small care staff implies security and contributes to increased client satisfaction. 
While the older persons were on the waiting list for a permanent place in a nursing home, the next of kin were constantly afraid and worried about what might happen to the older person. Their sense of responsibility increased, especially when they were not there to help. Feelings of inner conflict, guilt, anxiety, sorrow, fear, and loneliness arose. Emotions in the next of kin group have also been noted in previous research, showing their vulnerability ${ }^{[9,34-38]}$.

Those next of kin who care for a parent are mostly in the working age group of 45-64 years. The time pressure resulting from caregiving can cause problems for the next of kin with regard to work and can lead to strained relationships ${ }^{[8]}$. In the present study, most of the next of kin were working full-time, with high time pressure, exacerbated by a perceived lack of communication. They also experienced a lack of information when they had to contact a lot of people and agencies to find the help and the information they needed. Sand ${ }^{[8]}$ likewise found that the effort to coordinate various health supports around the old person is a common cause of negative stress in the family.

\section{Methodological considerations}

The focus in this study was to increase the understanding of the next of kin's experience of their life situation in connection with informal caregiving to older persons as a phenomenon; in other words, diagnosis-specific diseases/conditions of the older persons were not in focus.

The informal conversational interviews provided many opportunities to explore the meaning of what was being studied, expanding on information that was collected previously, moving in new directions, and seeking elucidation from various participants ${ }^{[39]}$. The informal interview is the most open-ended approach to interviewing, as it offers the maximum flexibility to pursue information in whatever direction appears to be appropriate. Interviewing the participants twice also offered the opportunity for the next of kin to make changes and to confirm that their points had in fact been understood in the correct way. It was a way of ensuring credibility. The time available for reflection between the first and the second interview enabled a deepening of the subsequent conversation ${ }^{[40]}$. In most of the second interviews, there was indeed such a deepening. To further strengthen credibility, we scrutinized and repeatedly discussed the results during the analytical process, including how the results should be presented, since a clear description of the approach enables the reader to assess the transferability. A peer debriefing session was conducted with other researchers, in order to provide an external check $^{[40]}$. Some older persons were not in a position to nominate a next of kin for participation ${ }^{[27]}$ because their next of kin either lived elsewhere or could not spare the time. Although we interviewed all the next of kin who were nominated, the convenience sampling can be seen as a restriction in the study. Another factor that can be seen as a restriction is that all the respondents were native Swedish speakers, and none was an immigrant with a different cultural background.

\section{Conclusions}

The present study highlights the strained life situation of next of kin caring for older persons, often with an imbalance seen in relations and demands in next of kin's daily life. Even though extensive research has previously been done in this field, there is a need for further research to give more attention to the next of kin's life situation and to find the means to support them in trying to balance the demands on them. Nolan et al.'s Partnership Model ${ }^{[21,22]}$ provides one way of doing this. This model is applied by holding meetings where the next of kin, the older person, and the staff have a chance to talk about their expectations concerning each other, their common desires, and the purpose of the care. The results of this study offer additional insight that is relevant to politicians' planning of health care for older persons, which takes into account the informal caregiver: the next of kin.

\section{Acknowledgement}

This study was supported by the Örebro Nutrition and Physical Activity Research Center for Optimal Health and Functionality through Life (NUPARC). 


\section{References}

[1] Organisation for Economic Co-operation and Development (OECD). Policies for healthy ageing: An overview. Health Working Papers No. 42. Directorate for Employment Labour and Social Affairs Health Committee. 2009. Available from: www.oecd.org/

[2] World Health Organization (WHO). World Health Statistics. WHO Library Cataloguing-in Publication Data. 2013. Available from: www.who.int/gho/publications/worldhealthstatistics/ENWHS2013Full.pdf

[3] European Commission (EU). Health-EU, My Health, Elderly[Internet]. 2013. Available from: $\mathrm{http} / / / \mathrm{ec}$.europa.eu/health-eu/myhealth/elderly/indexen.htm

[4] Swedish Institute of Public Health. Healthy Ageing in Europe. Lessons Learnt and Ways Forward[Internet], No. 24.2007. Available from: http://www.fhi.se

[5] Bloom DE, Boersch-Supan A, McGee P, Seike A. Population Aging: Facts, Challenges and Responses (Program on the Global Demography of Aging [PGDA], Working Paper No. 71). 2011. Available from:http:/www.hsph.harvard.edu/pgda/WorkingPapers/2011/PGDA_WP_71.pdf

[6] Lennartsson C, Heimerson I. Elderly people's health: Health in Sweden: The National Public Health 2012 Report. Chapter 5. Scandinavian Journal of Public Health. 2012; 40:95. PMid:23238403 http://dx.doi.org/10.1177/1403494812459468

[7] The National Board of Health and Welfare. Relatives who provide care to related parties - an extent and consequences. (Artikelnr 2012-8-15). 2012. Available from: http://www.socialstyrelsen.se/Lists/Artikelkatalog/Attachments/18811/2012-8-15.pdf In Swedish.

[8] Sand A-B. Relatives who combine paid work and family care. Systematic review. National Centre Relatives[Internet]. $2010: 1$. Available from:

http://www.anhoriga.se/Global/St\%C3\%B6d\%20och\%20kunskap/Publicerat/Kunskaps\%C3\%B6versikter/Dokument/Koversikt_ forvarvsarb.pdf In Swedish

[9] Lavela SL, Ather N. Psychological health in older adult spousal caregivers of older adults. Chronic Illness. 2010; 6, 67-80. PMid:20308352 http://dx.doi.org/10.1177/1742395309356943

[10] Grafström M. The Experience of Burden in the Care of Elderly Persons with Dementia. Dissertation. Department of Clinical Neuroscience and Family Medicine, Section of Geriatric Medicine, KarolinskaInstitute, Stockholm Gerontology Research Center and Department of Advanced Nursing. University of Umeå Sweden. 1994.

[11] Sällström C. Spouses’ Experiences of Living with a Partner with Alzheimer's Disease. Dissertation. Departments of Advanced Nursing, Geriatric Medicine, and Psychiatry, University of Umeå, Sweden. 1994.

[12] Walker A, Pratt C, Eddy L. Informal caregiving to ageing family members. A critical review. Family Relations. 1995 ; $44: 402-411$. http://dx.doi.org/10.2307/584996

[13] Sandberg J, Nolan MR, Lundh, U. The role of community staff in care home placement in Sweden. Journal of Clinical Nursing. 2002; 11(4): 488-497. PMid:12100645 http://dx.doi.org/10.1046/j.1365-2702.2002.00619.x

[14] White CL, Lauzon S, Yaffe MJ, Wood-Dauphinee S. Toward a model of quality of life for family caregivers of stroke survivors. Quality of Life Research. 2004; 13: 625-638. PMid:15130026 http://dx.doi.org/10.1023/B:QURE.0000021312.37592.4f

[15] Hellström I, Nolan M, Lundh U. Sustaining couplehood: Spouses' strategies for living positively with dementia. Dementia: The International Journal of Social Research and Practice. 2007; 6: 383-409. http://dx.doi.org/10.1177/1471301207081571

[16] Erlingsson CL, Magnusson L, Hanson E. Family caregivers' health in connection with providing care. Qualitative Health Research. 2012; 22(5): 640-655. PMid:22203389 http://dx.doi.org/10.1177/1049732311431247

[17] Stackfleth R, Diniz MA, Fhon JRS, Vendruscolo TRP, Fabricio-Whebe SCC, Marques S, Rodrigues RAP. Burden of work in caregivers of frail elders living at home. Acta Paulista de Enfermagem 2012; 25(5): 768-774. http://dx.doi.org/10.1590/S0103-21002012000500019

[18] Connell PJ. A Phenomenological Study of the Lived Experiences of Adult Caregiving Daughters and Their Elderly Mothers. Dissertation. Graduate School of the University of Florida. 2003.

[19] The National Board of Health and Welfare. Support for families requires strategy. Announcement Sheet[Internet]. 2009. Available from: http://www.socialstyrelsen.se/Lists/Artikelkatalog/Attachments/17837/2009-11-32.pdf In Swedish

[20] Andrén S, Elmståhl S. Effective psychosocial intervention for family caregivers lengthens time elapsed before nursing home placement of individuals with dementia: A five-year follow-up study. International Psychogeriatrics 2008; 20(6): 1177-1192. http://dx.doi.org/10.1017/S1041610208007503

[21] Nolan M, Grant G, Keady J, Lundh U. New directions for partnerships: Relationship-centered care. In Nolan M, Lundh U, Grant G, Keady J. Partnership in Family Care: Understanding the Caregiving Carer. Open University Press: Philadelphia; 2003. 
[22] Nolan MR, Brown J, Davies S, Nolan J, Keady J. The Senses Framework: Improving care for older people through a relationship-centered approach. Getting Research into Practice (GRIP) Report No. 2. Sheffield Hallam University Research Archive[Internet]. 2006. Available from: http://shura.shu.ac.uk/280/1/PDF_Senses_

[23] Erlingsson CL, Magnusson L, Hanson E. Carers health. Systematic review. National Centre, Relatives[Internet]. $2010: 3$. Available from:

http://www.anhoriga.se/Global/St\%C3\%B6d\%20och\%20kunskap/Publicerat/Kunskaps\%C3\%B6versikter/Dokument/Kunskapso versikt_halsa.pdf In Swedish

[24] Morse JM, Richards L. Readme First for a user's guide to qualitative methods. Thousand Oaks, Californien: Sage, cop. 2002

[25] Patton MQ. Qualitative Research \& Evaluation Methods. London: Sage Publications. 2002.

[26] Graneheim UH, Lundman B. Qualitative content analysis in nursing research: Concepts, procedures and measures to achieve trustworthiness. Nurse Education Today. 2004; 24(2): 105-112. PMid:14769454 http://dx.doi.org/10.1016/j.nedt.2003.10.001

[27] James I, Blomberg K, Liljekvist E, Kihlgren A. Meaningful Day for Older Persons in Municipality Care: Guidelines for the Care. School of Health and Medical Sciences, Örebro University, Örebro. Care and Services Committee, Örebro Municipality, Örebro Sweden. Submitted. 2013.

[28] Fossum B. Successful communication models, Chapter 7. In Fossum B. Ed. Communication, discussion and treatment in healthcare. Lund: Studentlitteratur. 2013. In Swedish

[29] Winqvist M. The meaning of call as support of relatives. Nationally Competence Centre Relatives[Internet]. 2011:1. Available from http://www.anhoriga.se/Global/St\%C3\%B6d\%20och\%20kunskap/Publicerat/Kunskaps\%C3\%B6versikter/Dokument/2011-1_Sa mtaletsbetydelse_NkA_WEBB.pdf In Swedish

[30] Häggström E, Skovdahl K, Fläckman B, Kihlgren LA, Kihlgren M. To feel betrayed and to feel that you are betraying the older residents: Caregivers' experiences at a newly opened nursing home. Journal of Clinical Nursing. 2004; 13: 687-696. PMid:15317508 http://dx.doi.org/10.1111/j.1365-2702.2004.00939.x

[31] Häggström E, Kihlgren A, Kihlgren M, Sörlie V. Relatives' struggle for an improved and more just care for older people in community care. Journal of Clinical Nursing. 2007; 16, 1749 -1757. PMid:17727593 http://dx.doi.org/10.1111/j.1365-2702.2007.01704.x

[32] Twigg J, Atkin K. Carers Perceived; Policy and Practice in Informal Care. Philadelphia; Open University Press. 2002.

[33] Ahlström G, Wadensten B. Family members' experiences of personal assistance given to a relative with disabilities. Health and Social Care in the Community. 2011; 19 (6): 645-652. PMid:21651637 http://dx.doi.org/10.1111/j.1365-2524.2011.01006.x

[34] Stotz P, Udén G, Willman A. Support for family carers who care for an elderly person at home; A systematic literature review. Scandinavian Journal of Caring Sciences. 2004;18(2): 111-119. PMid:15147473 http://dx.doi.org/10.1111/j.1471-6712.2004.00269.x

[35] Yap LKP, Seow CCD, Henderson LM, Goh YNJ. Family caregivers and caregiving in dementia. Reviews in Clinical Gerontology. 2005; 15(3-4): 263-271. http://dx.doi.org/10.1017/S0959259806001900

[36] Yajima Y, Tsutsui T, Nakajima K, Li TT, Takigawa T, Wang D-H, Ogino K. The effects of caregiving resources on the incidence of depression over one year in family caregivers of disabled elderly. Acta Medica Okayama. 2007; 61(2): 71-80. PMid:17471307

[37] Mannion E. Alzheimer's disease: The psychological and physical effects of the caregiver's role. Part 2. Nursing Older People. 2008; 20(4): 33-38 (28 ref).

[38] Sanders S, Ott CH, Kelber ST, Noonan P. The experience of high levels of grief in caregivers of persons with Alzheimer's disease and related dementia. Death Studies. 2008; 32: 495-523. PMid:18958942 http://dx.doi.org/10.1080/07481180802138845

[39] Bowling, A. Research Methods in Health: Investigating Health and Health Services. 3rd ed. Glasgow: Open University Press. 2009.

[40] Denzin NK, Lincoln YS. Eds. The Landscape of Qualitative Research. 4th ed. Los Angeles:Sage Publications. 2013. 